\title{
THE CONTRACTUAL INTERPRETATION OF TIPPING J
}

\author{
Matthew Barber
}

In the Supreme Court decision of Vector Gas Ltd v Bay of Plenty Energy Ltd, Tipping J put forward an approach to contact interpretation that, while indebted to that of Lord Hoffmann, was expressed differently and promoted the use of evidence of prior negotiations. Despite not gaining the support of any of the other sitting judges, this approach was swiftly taken up in the lower courts and, until recently at least, seems to have been accepted as representing New Zealand law. This article attempts a comprehensive examination of Tipping J's approach. It concludes that, while coherent in principle, the detail of the approach is flawed in a number of ways, especially the way in which evidence of subsequent conduct is assumed to work. The future of Tipping J's approach is considered.

\section{INTRODUCTION}

Vector Gas Ltd v Bay of Plenty Energy Ltd raised before the Supreme Court the issue of whether evidence of prior negotiations should be admissible for the purpose of interpreting a contractual document. ${ }^{1}$ Tipping $\mathbf{J}$ took the opportunity to set out a comprehensive statement of approach to contractual interpretation, which promoted the use of both prior negotiations and subsequent conduct. The disagreement between the Supreme Court judges in that case and the uncertainty that this has engendered is notorious. The outcome was that, despite not having the support of any of the other judges, the approach of Tipping $\mathrm{J}$ was almost immediately accepted in lower courts as the preeminent expression of New Zealand's approach to contractual interpretation. ${ }^{2}$ In this regard, it

* Senior Lecturer, School of Law, University of Canterbury.

1 Vector Gas Ltd v Bay of Plenty Energy Ltd [2010] NZSC 5, [2010] 2 NZLR 444.

2 For example the decision was quoted in no fewer than six Court of Appeal decisions issued in the same year as that of Vector Gas: D A Constable Syndicate 386 v Auckland District Law Society Inc [2010] NZCA 237, [2010] 3 NZLR 23 at [23]; ANZ National Bank Ltd v Tower Insurance Ltd [2010] NZCA 267 at [88]; Lumley General Insurance (NZ) Ltd v Body Corporate 205963 [2010] NZCA 316 at [27]; KC Securities Ltd $v$ Belgrave Finance Ltd (in rec) [2010] NZCA 409 at [31]; ALF No 9 Pty Ltd v Ellis [2010] NZCA 529 at [34]; and Trustees Executors Ltd v QBE Insurance (International) Ltd [2010] NZCA 608 at [31]-[33]. 
supplanted the judgment of Lord Hoffmann in Investors Compensation Scheme Ltd $v$ West Bromwich Building Society (ICS). ${ }^{3}$

Tipping J's approach held this position unequivocally until the recent Supreme Court decision in Firm PI 1 Ltd $v$ Zurich Australian Insurance Ltd. ${ }^{4}$ While declining to reconsider contractual interpretation generally, the majority of the Court in that case recited the approach of Lord Hoffmann rather than that of Tipping J. Since that decision, the frequency of references to the approach in ICS in New Zealand courts has increased, but it seems that the decision of Tipping $\mathrm{J}$ in Vector Gas remains ascendant. ${ }^{5}$

Given the importance of contractual interpretation to the resolution of civil disputes, particularly in the commercial realm, the uncertainty about which approach we should be following is an important issue. Perhaps more significant, however, is that it is not even clear from the cases how the two approaches differ, apart from that only one permits evidence of pre- and post-contract conduct. The complexity of the relevant part of Tipping J's judgment in Vector Gas contributes to this; while not long, it attempts to make sense of a number of aspects of interpretation including: linguistic context, private dictionaries, special meanings, apparent and contextual ambiguities, drafting and linguistic errors, prior negotiations and subsequent conduct, as well as the related issue of estoppel (and, to a much lesser extent, rectification). This article endeavours to analyse Tipping J's general statement on contractual interpretation in detail and to locate it in relation to the approach of Lord Hoffmann. This may help to bring the thinking of New Zealand courts on interpretation into focus, and to clarify the choice that must ultimately be made as to which approach, if either, we should follow.

\section{BACKGROUND TO VECTOR GAS}

The approach of Lord Hoffmann is embodied by five principles set out in ICS. In general terms, it is characterised by the abandonment of technicality and rules of interpretation and a willingness to resolve interpretation disputes by reference to the background context known or available to the parties at the time of contracting. To be clear, it is not that the alternative, more traditional approach prevents a court from inquiring into the background and purpose of an agreement. The difference is

3 Investors Compensation Scheme Ltd v West Bromwich Building Society [1998] 1 WLR 896 [ICS]. This decision was quoted in only one of the 2010 Court of Appeal judgments cited above: KC Securities, above $n$ 2 at [30]-[32]; and was also referred to in Trustees Executors Ltd, above n 2, at [31]-[32].

4 Firm PI 1 Ltd v Zurich Australian Insurance Ltd [2014] NZSC 147, [2015] 1 NZLR 432 at [60].

5 In 2015, the two approaches were each cited in a number of cases as reflecting New Zealand's position. See for example Brookmill Finance Ltd v Dawson [2015] NZHC 1682 at [24]; compare New Zealand Carbon Farming Ltd v Mighty River Power Ltd [2015] NZHC 1274 at [53]-[54]. The number of cases citing Tipping $\mathbf{J}$ in this period outnumber those referring to Lord Hoffmann. It may be significant, however, that the one major Court of Appeal decision in that year preferred Lord Hoffmann to Tipping J: AAI Ltd v 92 Lichfield Street Ltd (in rec and in liq) [2015] NZCA 559, (2015) 23 PRNZ 52 at [31]. 
that under Lord Hoffmann's approach, context can be relevant whether or not a document is ambiguous on its face, and that the plain meaning of such a document can give way if judged to be contrary to the commercial purpose of the agreement or mistaken.

What this approach does not permit, however, is reference to the negotiations between the parties leading up to agreement (nor their conduct subsequent to it). Lord Hoffmann reconsidered this issue in his final judicial statement on contractual interpretation in Chartbrook Ltd v Persimmon Homes $L t d{ }^{6}$ deciding that there was not sufficient reason to abandon the rule excluding prior negotiations. He commented that this means that: ${ }^{7}$

... parties are sometimes held bound by a contract in terms which, upon a full investigation of the course

of negotiations, a reasonable observer would not have taken them to have intended. But a system which

sometimes allows this to happen may be justified in the more general interest of economy and

predictability in obtaining advice and adjudicating disputes.

This has been a contentious area and amounts to an exception to his general approach. ${ }^{8}$

The principles set out by Lord Hoffmann in ICS were adopted in New Zealand by the Court of Appeal in Boat Park Ltd v Hutchinson, and represented the dominant approach to contractual interpretation here. ${ }^{9}$ The advent of the Supreme Court provided the opportunity for their reexamination. In 2007, in Wholesale Distributors Ltd v Gibbons Holdings Ltd, the exclusion of evidence of subsequent conduct was removed by this Court. ${ }^{10}$ Although Thomas $\mathbf{J}$ offered a full restatement of principle on contractual interpretation, the majority accepted that such evidence could be helpful in determining contractual meaning on the seemingly pragmatic basis that it may in some

6 Chartbrook Ltd v Persimmon Homes Ltd [2009] UKHL 38.

7 At $[41]$.

8 See for example Donald Nicholls "My Kingdom for a Horse: The Meaning of Words" (2005) 121 LQR 577; Alan Berg "Thrashing Through the Undergrowth" (2006) 122 LQR 354; and David McLauchlan "Contract Interpretation: What Is It About?" (2009) 31 Syd LR 1.

9 Boat Park Ltd v Hutchinson [1999] 2 NZLR 74. ICS was cited a number of times by the Court of Appeal, most notably in Pyne Gould Guinness Ltd v Montgomery Watson (NZ) Ltd [2001] NZAR 789; Manco Engineering Group Ltd v Timberjack Group OY CA369/01, 13 June 2002; Craggy Range Vineyards Ltd v Campbell [2008] NZCA 96; and Bay of Plenty Electricity Ltd v Vector Gas Ltd [2008] NZCA 338. A view contrary to the approach in ICS was expressed in Potter v Potter [2003] 3 NZLR 145 (CA) at [34], but was not accepted subsequently.

10 Wholesale Distributors Ltd v Gibbons Holdings Ltd [2007] NZSC 37, [2008] 1 NZLR 277. See also the decision of the Court of Appeal in Attorney-General v Dreux Holdings Ltd (1996) 7 TCLR 617. 
situations be helpful. ${ }^{11}$ Tipping $\mathbf{J}$ was one of these, although he found that such conduct must be shared or mutual in order to be considered by the court. ${ }^{12}$

\section{VECTOR GAS AND THE RESPONSE}

Vector Gas brought the issue of prior negotiations before the Supreme Court. All five of the sitting judges delivered substantive judgments. Tipping and Wilson JJ offered restatements of the general approach to contractual interpretation, McGrath $\mathrm{J}$ reaffirmed the English approach, and Blanchard and Gault JJ preferred to discuss general issues only insofar as necessary to determine the outcome of the case.

The decision of Tipping $\mathrm{J}$ presents an approach, like that of Lord Hoffmann, based on objectivity and context, but concludes that evidence of prior negotiations and subsequent conduct should be available to the court. That this quickly superseded the ICS decision in New Zealand courts may be because, apart from the admissibility of prior negotiations, the general approach of Tipping $\mathrm{J}$ is considered equivalent to that of Lord Hoffmann. ${ }^{13}$

The decision of the Supreme Court in Vector Gas has been roundly criticised by commentators. Jessica Palmer and Andrew Geddis chose it as the worst decision the Supreme Court had delivered, on the grounds that the Court left the law worse than it had found it, although much of this had to do with the lack of agreement between the five judges. ${ }^{14}$ The judgment of Tipping $\mathbf{J}$ specifically has been examined by Francis Dawson and David McLauchlan, which is particularly interesting since the two reach different conclusions about the best approach to interpretation. ${ }^{15}$

Dawson identifies two approaches to interpreting contracts. The first is the traditional approach, which seeks to give effect to the expressed intention of the parties: "When parties reduce their agreement into written form their intention is to express their agreement in writing and to shut out appeals to what has previously passed between them."16 Under this approach, the parties by executing a contractual document choose to be bound by the meaning of the words it contains. ${ }^{17} \mathrm{~A}$

11 Per Elias CJ, Tipping and Anderson JJ. Of the three, the analysis of Tipping $\mathbf{J}$ was by far the most detailed.

12 At [53] and [62].

13 See for example KC Securities, above n 2, at [31].

14 Jessica Palmer and Andrew Geddis "What Was That Thing You Said? The NZ Supreme Court's Vexing Vector Gas Decision" (2012) 31 UQLJ 287 at 303-304.

15 Francis Dawson "Contract Objectivity and Interpretation in the Supreme Court: A Review of Dysart Timbers Ltd v Neilson and Vector Gas Ltd v Bay of Plenty Energy Ltd" in A Stockley and M Littlewood (eds) The New Zealand Supreme Court: The First Ten Years (LexisNexis, Wellington, 2015) 219; and David McLauchlan "Contract Interpretation in the Supreme Court - Easy Case, Hard Law?" (2010) 16 New Zealand Business Law Quarterly 229.

16 Dawson, above $\mathrm{n} 15$, at 233-234.

17 At 235. 
court interpreting this document will be "fully apprised of the surrounding circumstances" in which the contract was made (not including prior negotiations), but where the meaning of the words is clear then this will not be displaced by context. ${ }^{18}$

The object of the second approach is to give effect to the intended meaning of the parties. Prior negotiations are highly relevant to this since they help to show what the parties meant to achieve. ${ }^{19}$ Under this approach, the ascertained meaning of contractual words may differ from their apparent meaning if a court determines that the words used do not reflect what the parties intended. Dawson holds both approaches to be logically defensible, but prefers the traditional approach on the practical basis that the second approach requires an investigation as to the whole of the background of an agreement before any conclusion about meaning can be drawn. ${ }^{20}$

The approach in ICS, Dawson states, represents an attempt to find a middle ground between these two positions that gives effect to the "apparently intended meaning of the words". ${ }^{21}$ It is not traditional, since it always permits the court to look beyond the meaning of the expressed words, and yet it is limited to the objectively available information. This he describes as a "heroic attempt to straddle the Grand Canyon", and identifies it as the source of much uncertainty in the area. ${ }^{22}$ Dawson considers that Tipping J's decision in Vector Gas is "deeply indebted" to the second approach to interpretation, and in relation to prior negotiations and special meaning "is a compelling working out of an approach seeking to give effect to the intended meaning". ${ }^{23}$ Yet there are, he suggests, some passages that have a greater affinity with the first position, and generally it seems that Tipping J's focus on objectivity means that he does not fully embrace the second.

McLauchlan's own views are unequivocally in favour of that second position. On his approach a court should give effect to the subjective beliefs of the parties as to meaning where these are shared. This is not necessarily, he argues, an exception or qualification of objectivity: ${ }^{24}$

To the contrary, I suggest that an objective approach, at least properly understood, requires implementation of a proven actual mutual intention. That intention is the objective intention, although surely it would be better to say that the objective principle has no application where actual mutual

18 At $234-235$ and 238 . See also 249.

19 At 239.

20 At 240

21 At $241-242$

22 At 242

23 At 247

24 David McLauchlan "Objectivity in Contract" (2005) 24 UQLJ 479 at 480 (emphasis in original). McLauchlan's views influenced Thomas $\mathrm{J}$ in his decision in Wholesale Distributors, above $\mathrm{n} 11$, at [112][113]. 
intention is established. In other words, while a meeting of the minds or consensus ad idem is not necessary for contract formation, it is surely sufficient.

It follows that McLauchlan is in favour of allowing evidence of prior negotiations.

In his article examining the decision in Vector Gas, McLauchlan discussed the decision of Tipping $\mathrm{J}$ in some detail. He considered it "broadly consistent" with his own favoured approach. ${ }^{25}$ He was, however, critical of the use of an "unnecessary and confusing array of labels or concepts to give legal effect to an objectively determined consensus as to meaning". ${ }^{26}$ Many of these came from the English cases, and McLauchlan considered them redundant in the more liberal approach of Tipping J. ${ }^{27}$ McLauchlan seemed to consider that Tipping $\mathrm{J}$ dedicated considerable effort to demonstrating the agreement between his approach and that of Lord Hoffmann in Chartbrook, and that this led the New Zealand judge to mistake his Lordship's position in a number of instances. ${ }^{28}$

\section{THE DECISION}

If Tipping $\mathrm{J}$ was concerned to agree with Chartbrook, or the modern English approach generally, then it is curious that he did not simply use Lord Hoffmann's words. Tipping J may have been encouraged to present his own views by the need to justify the use of prior negotiations (and subsequent conduct), yet the exclusion of prior negotiations is in the nature of an exception under the ICS approach; according to Lord Hoffmann is the only thing that prevents it from completely assimilating "the way in which such documents are interpreted by judges to the common sense principles by which any serious utterance would be interpreted in ordinary life". ${ }^{29}$ For that reason it would have been possible for Tipping $\mathrm{J}$ to adopt the ICS approach apart from the exclusion, resulting in a more internally consistent system of interpretation than ICS itself, and yet his restatement of approach in his own terms was complete. In order to analyse the general parts of his judgment here, I will examine the various aspects or themes of the approach in turn, roughly matching the order in which they are presented.

\section{A General Approach}

Tipping J's statement of general principle is contained in the first part of [19]: ${ }^{30}$

\footnotetext{
25 McLauchlan, above n 15, at 244.

26 At 247

27 At 251 .

28 See 245,247 and 251.

29 ICS, above n 3, at 912.

30 Vector Gas Ltd, above n 1 (citations omitted).
} 
The ultimate objective in a contract interpretation dispute is to establish the meaning the parties intended their words to bear. In order to be admissible, extrinsic evidence must be relevant to that question. The language used by the parties, appropriately interpreted, is the only source of their intended meaning. As a matter of policy, our law has always required interpretation issues to be addressed on an objective basis. The necessary inquiry therefore concerns what a reasonable and properly informed third party would consider the parties intended the words of their contract to mean. The court embodies that person.

In essence this passage seems to be organised as two premises and a conclusion, so that:

(1) the object of interpretation is to establish the meaning intended by the parties;

(2) evidence employed for this purpose must be objective; and so

(3) the necessary inquiry is what a reasonable and properly informed third party would consider the parties intended.

The role of the third sentence in the passage is not clear; it doesn't connect obviously with either the preceding or following sentence. Dawson suggests that it undermines the earlier focus on intended meaning. ${ }^{31}$ In this way, it could be that the sentence suggests some limit on the use of extrinsic material, although this conflicts sharply with the remainder of Tipping J's judgment and, if right, makes the phrase "appropriately interpreted" redundant. Alternatively, it may be that the "language" referred to is not limited to the words of the contractual document but includes all the language used by the parties throughout the contracting process, so that the sentence serves to introduce the following point on objectivity. But this seems a curious use of "language" in this context, and ignores other background materials that are relevant to interpretation. A third possibility is that the language in question is the contractual language and the interpretation is the whole process of interpretation, but then the sentence offers that the interpretation of contractual words through intended meaning involves only the contractual words appropriately interpreted, which is circular. It is unclear which of these readings is intended.

The overall approach of Tipping $\mathrm{J}$ in this passage is clearly contextual and objective, in a similar way to that of Lord Hoffmann. Although set out in five principles, his Lordship's essential message is encapsulated in the first, that: ${ }^{32}$

Interpretation is the ascertainment of the meaning which the document would convey to a reasonable person having all the background knowledge which would reasonably have been available to the parties in the situation in which they were at the time of the contract.

Putting aside the potential for different standards by which the reasonable person would be informed (which are considered below), these approaches are functionally equivalent except in one respect: the ICS approach involves a reasonable person ascertaining the meaning of the document; Tipping

31 Dawson, above n 15, at 245-246.

32 ICS, above n 3, at 912. 
J's approach involves a reasonable person ascertaining the meaning of the document that the parties intended. This shift of focus from the document to the parties suggests that Tipping $\mathrm{J}$ is closer to Dawson's second position than is Lord Hoffmann. In practical terms this may mean a greater focus on the interests of the parties relative to the words they agreed upon, albeit through objective evidence, and that the approach is more amenable to evidence of prior negotiations.

\section{$B$ Objectivity and the Role of Context}

Objectivity is clearly very significant in Tipping J's judgment. The hypothetical person who is tasked with finding the intended meaning of a contract is reasonable and has information both internal and external to the contractual document. Tipping goes on in [19] to state:

\footnotetext{
To be properly informed the court must be aware of the commercial or other context in which the contract was made and of all the facts and circumstances known to and likely to be operating on the parties' minds. Evidence is not relevant if it does no more than tend to prove what individual parties subjectively intended or understood their words to mean, or what their negotiating stance was at any particular time.
}

This is the primary statement in the judgment identifying the knowledge that the reasonable person, and so the court, will be able to access. There are two parts to this: contex tual material and material operating on the parties' minds. The first indicates the background to the transaction: those facts, significant and trivial, that are foundational to the agreement and that are obviously known by the parties. This is the kind of information that may not have ever been expressed, but that each possesses and that each reasonably believes the other to possess.

The knowledge requirement in the second part should probably be understood, like in the ICS approach, to mean that the information was reasonably available to the parties. To require the court to inquire as to actual knowledge would be inconsistent with the objective nature of the approach. That the information must be likely to be operating on the parties' minds probably reflects that the reasonable person is searching for the meaning they intended. What is excluded from consideration is evidence of the subjective intentions or understandings of the parties as these are known only to the parties who hold them. If, however, the subjective intention of one party is communicated to the other then this is potentially available to the reasonable person, a point that becomes important in relation to other aspects of Tipping J's decision.

The information available to the court amounts to the context that informs the process of interpretation. Tipping $\mathbf{J}$ made it clear that there is no ambiguity threshold for considering external context in interpreting contracts and that it is "always permissible to go outside the written words for the purpose of identifying the context in which the contract was made". ${ }^{33}$ This means that it is also always possible for the plain meaning of an express contractual provision to be upset by reference to

33 Vector Gas Ltd, above n 1, at [23]. 
context. ${ }^{34}$ These ideas are similar to those of Lord Hoffmann in ICS and Chartbrook and reflect the modern approach to interpretation. ${ }^{35}$

\section{The Force of Contractual Writing}

Tipping J offers a conception of contractual writing, when in [20] he states that:

The common law focuses strongly on the agreement in its final form as representing the ultimate consensus of the parties. Hence it is regarded as irrelevant how the parties reached that consensus. To inquire into that process would not be consistent with an objective inquiry into the meaning of a document which is generally designed to be the sole record of the final agreement.

Given that the judgment favours the admission of prior negotiations, it is strange to declare that how the parties reached agreement is irrelevant. This passage is from a part of the judgment that justifies the exclusion of the parties' subjective beliefs. It supports that conclusion, in that it upholds the written agreement as the source of contractual rights over subjective beliefs. But if the final expression of the agreement is the ultimate consensus of the parties then this may also justify giving less weight to the objective context of the agreement, or, at least where the contractual wording is plain, excluding it altogether. ${ }^{36}$

Yet Tipping $\mathbf{J}$ seems to be affirming the importance of the final written agreement in order to exclude subjective intentions rather than extrinsic objective material. This is suggested by his later statement that: ${ }^{37}$

Although the common law takes the view that it is only the final written contract which records the

ultimate consensus of the parties, the way that consensus is expressed may be based on an agreement as

to meaning reached during negotiations.

Tipping J may be correct to use this point to exclude subjective but not objective context, but it is not clear from his judgment why that this is.

This relates to the more general point about the significance of the contractual words agreed to by the parties. Notwithstanding the ubiquity of contextual material in current approaches, the process of contract interpretation remains one of interpreting the words actually used and agreed to by the parties. Expressions of the modern contextual approach will often include statements that emphasise the importance of the written words (and their plain meaning). In this vein, Lord Hoffmann has noted, for example, that "we do not easily accept that people have made linguistic

34 At [24].

35 Particularly principles 4 and 5 from ICS, above n 3 .

36 Similar to the preferred approach of Dawson, above n 15, at 234-235.

37 Vector Gas Ltd, above n 1, at [28]. 
mistakes, particularly in formal documents" 38 and that "the primary source for understanding what the parties meant is their language interpreted in accordance with conventional usage". ${ }^{39}$ Tipping $\mathbf{J}$ makes this point more strongly in saying: ${ }^{40}$

Subject to the private dictionary and estoppel exceptions to be mentioned below, it is fundamental that words can never be construed as having a meaning they cannot reasonably bear. This is an important control on the raising of implausible interpretation arguments. Furthermore, the plainer the words, the more improbable it is that the parties intended them to be understood in any sense other than what they plainly say.

This gives weight to plain contractual language, but, more significantly, it also precludes the court from giving a meaning that words cannot reasonably bear, except by estoppel and private dictionary. This statement would no doubt be viewed positively by some as setting a clear limit on the scope of context, but, as McLauchlan points out, it is difficult to take seriously. In his words, the significance of the estoppel and private dictionary exceptions (discussed below) "largely deprive the 'fundamental' proposition of meaningful content". ${ }^{41}$

Even putting estoppel and private dictionaries aside, it is not clear that Tipping J's statement is consistent with his general approach. A fully informed reasonable person might determine that the parties intended contractual words to have a meaning that they cannot reasonably bear. This may be regarded as the correcting of errors of expression, which is available to the reasonable person in some circumstances. ${ }^{42}$ Some such situations will be discussed in the following section, but for now it seems that Tipping J's strong statement of limitation on the contextual approach is not simply undermined by some broad exceptions, but rather is potentially inconsistent with his general approach. It seems unlikely that it was intended to act as an extrinsic restriction on that approach, which would mean that, as a statement about how interpretation is to work, it is incorrect.

\section{Private Dictionaries, Estoppel and Special Meaning}

Tipping J describes a private dictionary meaning as being: ${ }^{43}$

38 ICS, above n 3, at 912.

39 Bank of Credit and Commerce International SA (in liq) v Ali (No 1) [2001] UKHL 8 at [39].

40 Vector Gas Ltd, above n 1, at [23] (emphasis in original, citations omitted).

41 McLauchlan, above n 15, at 249.

42 See Vector Gas Ltd, above n 1, at [33] and the final sentence of [21]. McLauchlan identifies error correction as an exception to the proposition additional to the private dictionary and estoppel exceptions, above $\mathrm{n} 15$, at 249.

43 Vector Gas Ltd, above n 1, at [25]. 
... a meaning the words linguistically cannot reasonably bear. It is, nevertheless, open to a party to show that, despite that fact, the parties intended their words to have that special meaning for the purposes of their contract. This represents a consensual parallel with cases in which words have a special meaning by trade custom.

There is no overlap, then, between private and real dictionaries, since the former include only the unconventional use of words. In a later part of the judgment, Tipping $\mathrm{J}$ explains that: ${ }^{44}$

A special meaning exists when the words used, even after the contractual context is brought to account, are linguistically still capable of only one meaning or are wholly obscure; but it is nevertheless evident from the objective context that the parties, by custom, usage or agreement, meant their words to bear a meaning which is linguistically impossible ...

This brings the difficulty with private dictionaries into focus: if the reasonable person, upon considering the objective context of a contractual provision, decides that the parties intended a meaning that its words cannot reasonably bear, then this is a special or private dictionary meaning. But this is the meaning it will be given under the general approach anyway. Contrary to the pas sage considered in the previous section, a private dictionary meaning is not an exception to the general approach to interpretation, since a reasonable person inquiring after the intended meaning of contractual words might conclude that an unusual or unconventional usage was intended; rather it is within the general approach set out by Tipping $\mathrm{J}$ in [19]. ${ }^{45}$ This conclusion further undermines the assertion that words cannot be construed as having a meaning that they cannot reasonably bear.

Tipping $\mathbf{J}$ also states that a private dictionary meaning can be regarded: ${ }^{46}$

... as a linguistic example of estoppel by convention. The estoppel prevents the accepted special meaning from later being disavowed. Estoppels can also arise in interpretation cases not involving a special meaning. They are then normally based on a common assumption or representation as to meaning.

This suggests that private dictionary meanings are applications of estoppel by convention, where the meaning that has been assumed or agreed between the parties is one that is unconventional or unusual.

44 At [33].

45 This point was made by McLauchlan, above $\mathrm{n} 15$, at 250 .

46 Vector Gas Ltd, above n 1, [25] (citations omitted). He makes a similar statement at [34]: "Although an estoppel will usually arise from the adoption of a special meaning, it is in cases where words are capable of bearing more than one meaning that estoppel is likely to have its primary application. A party may be estopped from denying that one of two possible meanings was the meaning the parties intended their words to bear." 
Both estoppel and private dictionaries are prominent in the recent English case law on interpretation. In general terms, estoppel by convention may arise where: ${ }^{47}$

... parties to a contract, by their course of dealing, place a particular interpretation on the terms of the contract, and then each, to the knowledge of the other, conducts their mutual affairs on the faith of that interpretation

This is a relatively recently recognised addition to contractual interpretation and was described by Lord Hoffmann in Chartbrook, alongside rectification, as a safety net that assists the court in overcoming the problems inherent in excluding evidence of prior negotiations, in particular that the court may be forced to give an interpretation that the conduct of the parties shows was not intended. ${ }^{48}$

Lord Hoffmann also discussed private dictionary meanings in that case, although without linking them to estoppel. His Lordship found it open to parties to show that they "habitually used words in an unconventional sense in order to support an argument that words in a contract should bear a similar unconventional meaning". ${ }^{49}$ The restriction of private dictionaries to unconventional usages was a necessary step for Lord Hoffmann, in that if they could include conventional usage then they would undermine the exclusion of prior negotiations. McLauchlan reveals the incongruity of this by asking: 50

Why is it that the court can admit evidence that, say, the parties always, or for a particular transaction, used the word "apples" to mean "pears", but not evidence that they used words in one of two conventional senses?

As McLauchlan also recognised, this uncomfortable distinction is completely unnecessary for Tipping J, who allows evidence of prior negotiations. ${ }^{51}$

Tipping $\mathrm{J}$ stated that private dictionary meanings had to be determined objectively. ${ }^{52}$ Presumably this is also true of estoppel arguments generally, both because there is no reason to think they should be any different and because the basis of this form of estoppel is the knowledge of each party that the other acts in belief of the same meaning. This being the case, McLauchlan's

47 Peter Young, Clyde Croft and Megan Smith On Equity (Thomson Reuters, Sydney, 2009) at [12.100].

48 Chartbrook, above n 5, at [40]-[41]. Modern usage stems from Amalgamated Investment \& Property Co Ltd v Texas Commerce International Bank Ltd [1982] QB 84; and Norwegian American Cruises A/S v Paul Mundy Ltd [1988] 2 Lloyd's Rep 343 (CA).

49 Chartbrook, above n 5, at [45].

50 McLauchlan, above n 15, at 248.

51 At 250 .

52 Vector Gas Ltd, above n 1, at [26]. 
conclusion that estoppel and private dictionary arguments are made redundant by Tipping J's general approach to interpretation is irresistible; it is difficult to conceive a situation where an estoppel would be needed to protect a meaning that would otherwise not be given effect. By presenting estoppel and private dictionaries as being separate to the ordinary process of interpretation, Tipping $\mathrm{J}$ has missed the opportunity to present an approach that is both simpler and more internally consistent than that of Lord Hoffmann.

\section{E Prior Negotiations and Subsequent Conduct}

The general approach of Tipping $\mathrm{J}$ in Vector Gas is well suited to include evidence of negotiations between the parties prior to agreement. He begins by defining what is meant by prior negotiations: ${ }^{53}$

\footnotetext{
Sometimes the concept seems to be used as if it encompassed all conduct and circumstances associated with negotiations towards the formation of a contract. It is necessary, however, to distinguish between the subjective content of negotiations; that is, how the parties were thinking, their individual intentions and the stance they were taking at different stages of the negotiating process on the one hand, and, on the other, evidence derived from the negotiations which shows objectively the meaning the parties intended their words to convey. Such evidence includes the circumstances in which the contract was entered into, and any objectively apparent consensus as to meaning operating between the parties.
}

It is plain here that the inclusion of prior negotiations is meant to be in accordance with the general principle of interpretation, that is with what the reasonable person would conclude was the parties' (objective) intention. ${ }^{54}$ This includes any apparent agreement as to meaning, since this is "an objectively determinable fact". ${ }^{55}$ Evidence of the latter amounts to "linguistic" context, which Tipping J contrasts with the "factual" context generally available for contractual interpretation. ${ }^{56}$

This would allow the courts to have access to any communications between the parties prior to agreement, as well as documents related to the final agreement, such as previous drafts of the contractual document. Exactly what any changes between a draft and the final written agreement mean in any particular case is a matter for the court to determine, and it is always open for a judge to conclude that a change has no significance in the context of the agreement. Similarly, although objective evidence here includes any communication between the parties, a court may conclude that a communication, even if expressly about the meaning of a contractual provision, is not relevant to the determination of that meaning. Such a communication may merely reflect the view of one party, for example, or may have been superseded by subsequent negotiations or by the agreement to the

53 At [27].

54 At [29].

55 At [32].

56 At [29]. 
contract; the ultimate agreement to a written document may, in the circumstances, overwhelm any prior discussion.

This approach extends to evidence of the conduct of the parties after the agreement is reached. Tipping J comments that: ${ }^{57}$

There is no logical reason why the same approach should not be taken to both post-contract and pre-

contract evidence. The key point is that extrinsic evidence is admissible if it tends to establish a fact or

circumstance capable of demonstrating objectively what meaning both or all parties intended their words

to bear.

There is, however, one important difference between pre-contract and post-contract evidence, namely that conduct that occurs subsequent to the parties reaching agreement cannot influence that agreement, unlike prior negotiations. Tipping $\mathrm{J}$ considered the use of subsequent conduct in interpretation in Wholesale Distributors Ltd v Gibbons Holdings Ltd, saying that such evidence "is directed to the original meaning; that is, the meaning of the contract when it was signed". ${ }^{58} \mathrm{He}$ went on to say: $:^{59}$

It can fairly be said that when the issue is examined as at the date of the court hearing, the shared conduct of the parties in the performance of their contract is a part of the surrounding circumstances. The only difference is that post-contract conduct cannot have informed the meaning of the parties' words at the time they contracted, but it can retrospectively have a legitimate bearing on that meaning. There is insufficient reason in principle to insist on a date of contract focus, albeit the ultimate criterion for ascertaining contractual intention remains the objective meaning of the words of the contract at that date. The horizon has expanded but the subject of the search remains the same.

Tipping J concluded in Wholesale Distributors that evidence of subsequent conduct may often be more useful than prior negotiations on the basis that such evidence "that logically indicates that at the time they contracted the parties attached a particular meaning to the words in dispute can be good evidence that a later attempt by one party to place a different meaning on those words is unpersuasive". 60

Since the "legitimate bearing" that Tipping J states that evidence of subsequent conduct can retrospectively have on the intended meaning of contractual words cannot be one of influence, it must instead be one of reflection; the subsequent conduct of the parties can reflect or manifest the intention the parties held at the moment of agreement. This conduct, then, can be used to indicate to

57 At [31].

58 Wholesale Distributors Ltd, above n 10, at [59].

59 At [61].

60 At [62]. 
the reasonable person the intended meaning of contractual words. The problem with this reasoning is that the intention being reflected by subsequent conduct may be the subjective intentions of the party or parties engaging in the conduct and, as such, would not be relevant to the process. Prior to such conduct, the intention that it supports will either be subjective or there will have been an earlier act that, if prior to contracting, will be the more appropriate evidential basis for the conclusions of the reasonable person as to meaning. On this basis, evidence of subsequent conduct will be relevant only if it serves to confirm pre-contractual knowledge for which there is insufficient direct evidence.

Tipping J required in Wholesale Distributors that evidence of subsequent conduct be shared or mutual, a point that was criticised by Thomas $\mathrm{J}$ in that case. ${ }^{61}$ In Vector Gas, Tipping $\mathrm{J}$ emphasised instead that the use of this evidence be in line with his general approach to interpretation. ${ }^{62}$ The requirements of this approach can help to illustrate the problems with using subsequent conduct. Of the two forms of admissible context, evidence of such conduct would not be part of the general background, but rather must be within "all the facts and circumstances known to and likely to be operating on the parties' minds". ${ }^{63}$ But this information must be known and operating at the point of contracting, which Tipping $\mathbf{J}$ emphasised is the point at which the intention of the parties is being considered. Subsequent conduct can only be relevant, then, in that it indicates information that was "known to and likely to be operating on the parties' minds" at the point of agreement.

Much of the evidence referred to in such cases is of the post-contract conduct of one party showing that they held a belief about the meaning of the contract that they later deny is correct. ${ }^{64} \mathrm{~A}$ reasonable person might infer from this that the party held that earlier belief at the point of contracting, but this would only amount to evidence that tends "to prove what individual parties subjectively intended" and so would not be relevant. ${ }^{65}$ Put another way, there is no evidence that the other party knew that this was a belief held by the first. As such, this fact was not known and likely operating on (both) their minds, and so is not available to the reasonable person as valid context to the agreement. If the first party had communicated this understanding to the other party prior to contracting then this information would then be relevant, but then the more significant evidence would be of a pre-contractual nature. Evidence of such subsequent conduct would be useful only if it can help to show that the information was jointly held at the time of contracting.

The corollary of this conclusion is that parties are entitled to claim that contractual words have a meaning contrary to that which they believed or intended at the moment of agreement. This is a

61 At [52]-[53] and [134]-[137].

62 Vector Gas Ltd, above n 1, at [30].

63 At [19].

64 Much of the evidence in Wholesale Distributors, above n 10, was of this nature.

65 Vector Gas Ltd, above n 1, at [19]. 
consequence of adopting an objective approach to interpretation, and is analogous to a party claiming that a contract has been formed by their conduct amounting to the acceptance of the offer, even though they never held the actual intention to accept.

Shared post-contract conduct has a stronger case for relevance to interpretation, yet suffers from the same problem. Consider the situation where the parties perform the contract in a way that corresponds with one particular interpretation and contradicts another. From this conduct, a court might infer that each party believed when contracting that this interpretation was correct. But this may only reflect that both parties held the same subjective belief at that point in time. What is missing is that each party knew that this was the meaning accepted by the other.

While McLauchlan may find a common actual intention to be a sufficient basis for interpretation, it is not clear that Tipping $\mathrm{J}$ intended to reach the same conclusion in either Wholesale Distributors or Vector Gas. The closest he gets to expressing agreement with this in Vector Gas is at [31] where he states that extrinsic evidence is admissible when it is "capable of demonstrating objectively what meaning both or all parties intended their words to bear". It is possible that this means that objective evidence, such as subsequent conduct, may be useful if it shows that there was a coincidence of the parties' subjective beliefs as to meaning. ${ }^{66}$ But this seems unlikely when considering Tipping J's general statement of approach. It would mean that the rule that the court is aware of "all the facts and circumstances known to and likely to be operating on the parties' minds" would include each party's subjective beliefs where they agree with that of the other party, even though the fact that one party holds a particular belief is different from the fact that the other party does. It would also mean that the stated irrelevance of evidence that "does no more than tend to prove what individual parties subjectively intended" would be have to be read with singular weight on "individual", as evidence that establishes the subjective beliefs of both parties, or of one party where there is separate objective evidence that this is shared, would be admissible. It is not entirely clear what Tipping $\mathbf{J}$ was intending in this regard, but were he intending a meaning that differed so markedly from the approach in ICS and which placed strain on some of the central elements of his approach, it would be expected that he would do so plainly.

This conclusion means that evidence of subsequent conduct will be relevant only if it helps to prove the objective intention of the parties at the time of agreement. Evidence that one or both parties held a particular intention is irrelevant unless it can be shown that the parties together knew of this intention, such as if there was an agreement as to meaning. Evidence of subsequent conduct,

66 At a number of points in his judgment, Tipping $\mathrm{J}$ focuses on objective or subjective evidence rather than objective or subjective intention of the parties, which might suggest that objective evidence of subjective intentions could be relevant. Consider for example where he distinguishes between subjective individual intentions and evidence "which shows objectively the meaning the parties intended". It might be significant that he uses the latter expression rather than identifying evidence "which shows the meaning the parties objectively intended": Vector Gas Ltd, above n 1, at [27]. 
then, must reflect the pre-contractual agreement of the parties as to meaning, and cannot be used to show what the parties subjectively believed when they contracted or what passed between them subsequently. There may be, however, a separate use for evidence of a post-contractual agreement as to meaning. If there is conduct that shows that both parties post-contractually held the same belief about the meaning of a contract and that each relied on this to the knowledge of the other then, although this would not be relevant to interpretation, it may be a suitable situation in which to apply an estoppel by convention. Although the liberal approach of Tipping $\mathbf{J}$ may remove the need for this estoppel in relation to prior negotiations, the issues with subsequent conduct considered above may give scope for its use in such circumstances.

\section{CONCLUSION}

There is much that is curious about the phenomenon of Tipping J's decision in Vector Gas. Instead of adopting the approach of Lord Hoffmann (without the exclusion of prior negotiations), he chose to restate the law of contractual interpretation on terms that are largely his own, while at the same time emphasising agreement with Lord Hoffmann in a number of footnotes. Despite being the decision of only one judge, subsequent courts largely accepted this as the correct approach to contractual interpretation, perhaps on the basis of it being New Zealand's own expression of a modern contextual approach that allows for evidence of prior negotiations and subsequent conduct.

Perhaps most curious is that the flaws in Tipping J's approach have undoubtedly contributed to this acceptance: the strong (but ultimately mistaken) statement about the limits of the interpretation process addresses the common concern that the modern approach allows courts to stray too far from the agreed words of the parties; the (unnecessary) focus on estoppel and private dictionaries matches the importance given to these features by both Lord Hoffmann and the other sitting judges in Vector Gas; and the (uncertain) basis for the use of evidence of subsequent conduct agrees with the approach from the Supreme Court decision in Wholesale Distributors. To some extent, then, Tipping's judgment in Vector Gas has become highly influential in New Zealand courts at the cost of missing the opportunity to present an approach to contractual interpretation that is simpler and more internally consistent than that which has developed in English law. Although such an alternative may not have been so immediately successful, it may have encouraged a focussed and explicit discussion about the approach we should apply.

The influence that Tipping J's judgment has enjoyed may be on the wane. The majority decision of the Supreme Court in Firm PI 1 Ltd v Zurich Australian Insurance Ltd, by identifying Lord Hoffmann's formulation as expressing the general approach may indicate that lower courts should not look to Tipping J's judgment as being the primary expression of New Zealand's approach. ${ }^{67}$ This will only become clear, however, when the Supreme Court again examines the principles of contractual interpretation.

67 Firm PI 1 Ltd, above n 4, at [60]-[63]. 
Regardless of how Tipping J's approach is treated in future, there are two general insights about the current state of contractual interpretation that can be drawn from it. The first is that, despite its vast influence, plausible alternatives to Lord Hoffmann's formulation of general approach are possible. Tipping J presents one that reconnects with the intention of the parties, a concept eschewed by Lord Hoffmann, and which may represent a clearer conceptual basis for ascertaining the legal effect of contractual words. The second insight is that an approach that is defined by a single overarching principle is considerably undermined where additional content contradicts or appears to contradict that principle. This is the case with much of the special meaning and estoppel content in Tipping J's approach, and also with the prior negotiations exception in that of Lord Hoffmann. Both of these approaches offer a coherent single statement of principle that identifies a contextual approach to contract law. Committing to either of these fully would mean that the interpretation debate could then move from determining the best general approach to asking how best to apply the approach adopted. 